\title{
Author Correction: PLK2 Plays an Essential Role in High D-Glucose- Induced Apoptosis, ROS Generation and Inflammation in Podocytes
}

\author{
Hong-hong Zou ${ }^{1}$, Ping-ping Yang ${ }^{1}$, Tian-lun Huang ${ }^{1}$, Xiao-xu Zheng ${ }^{2}$ \& Gao-si Xu ${ }^{1}$ \\ Correction to: Scientific Reports https://doi.org/10.1038/s41598-017-00686-8, published online 27 June 2017 \\ In the original version of this Article, affiliation 2 was inadvertently included. The correct affiliations are listed \\ below:
}

Department of Nephrology, the Second Affiliated Hospital of Nanchang University, No. 1 Minde Road, Nanchang, 330006, P.R. China.

Hong-hong Zou, Ping-ping Yang, Tian-lun Huang \& Gao-si Xu

Department of Medicine, the George Washington University, Washington, DC20052, USA.

Xiao-xu Zheng

This error has now been corrected in the PDF and HTML versions of the Article.

(i) Open Access This article is licensed under a Creative Commons Attribution 4.0 International Cicense, which permits use, sharing, adaptation, distribution and reproduction in any medium or format, as long as you give appropriate credit to the original author(s) and the source, provide a link to the Creative Commons license, and indicate if changes were made. The images or other third party material in this article are included in the article's Creative Commons license, unless indicated otherwise in a credit line to the material. If material is not included in the article's Creative Commons license and your intended use is not permitted by statutory regulation or exceeds the permitted use, you will need to obtain permission directly from the copyright holder. To view a copy of this license, visit http://creativecommons.org/licenses/by/4.0/.

(C) The Author(s) 2018

\footnotetext{
${ }^{1}$ Department of Nephrology, the Second Affiliated Hospital of Nanchang University, No. 1 Minde Road, Nanchang, 330006, P.R. China. 'Department of Medicine, the George Washington University, Washington, DC20052, USA. Hong-hong Zou and Ping-ping Yang contributed equally to this work. Correspondence and requests for materials should be addressed to G.-s.X. (email: gaosi_xu@163.com)
} 